\title{
Involvement of Smad3 phosphoisoform-mediated signaling in the development of colonic cancer in IL-10-deficient mice
}

\author{
DAISAKU HACHIMINE ${ }^{1}$, KAZUSHIGE UCHIDA $^{1}$, MASANORI ASADA $^{2}$, AKIYOSHI NISHIO $^{2}$, \\ SEIJI KAWAMATA ${ }^{1}$, GO SEKIMOTO ${ }^{1}$, MIKI MURATA ${ }^{1}$, HIDEO YAMAGATA $^{1}$, KATSUNORI YOSHIDA ${ }^{1}$, \\ SHIGEO MORI ${ }^{1}$, YOSHIYA TAHASHI ${ }^{1}$, KOICHI MATSUZAKI ${ }^{1}$ and KAZUICHI OKAZAKI ${ }^{1}$ \\ ${ }^{1}$ Third Department of Internal Medicine, Kansai Medical University, Moriguchi, Osaka; \\ ${ }^{2}$ Department of Gastroenterology, Graduate School of Medicine, Kyoto University, Kyoto, Japan
}

Received February 7, 2008; Accepted March 19, 2008

\begin{abstract}
Chronic inflammation predisposes to cancer. Transforming growth factor (TGF)- $\beta$, a multifunctional protein, suppresses the growth of normal colonic epithelial cells, whereas it stimulates the proliferation of cancer cells. Interleukin (IL)-10-deficient mice, which develop colitis and colorectal cancer, show an increased level of plasma TGF- $\beta$. Although TGF- $\beta$ may be a key molecule in the development of colon cancer arising from chronic colitis in IL-10-deficient mice, the role of TGF- $\beta$ still remains unclear. TGF- $\beta$ activates not only TGF- $\beta$ type I receptor (TßRI) but also c-Jun $\mathrm{N}$-terminal kinase (JNK), which converts the mediator Smad3 into two distinctive phosphoisoforms: C-terminally phosphorylated Smad3 (pSmad3C) and linker-phosphorylated Smad3 (pSmad3L). We studied C57BL/6-IL-10-deficient mice $(n=18)$ at 4 to 32 weeks of age. We investigated histology, and $\mathrm{pSmad} 2 / 3 \mathrm{~L}, \mathrm{pSmad} / 3 \mathrm{C}$, and $\mathrm{p} 53$ by immunohistochemistry. pSmad3L staining was detected in the cancer cells in all 10 mice with colonic cancer and in the epithelial cells in 7 of 12 mice with colonic dysplasia, but not in the normal or colitic mice. $\mathrm{pSmad} 3 \mathrm{c}$ was detected without any significant difference between stages. p53 was weakly stained in a few cancer cells in 5 out of 10 mice. Smad3L signaling plays an important role in the carcinogenesis of chronic colitis in IL-10-deficient mice.
\end{abstract}

\section{Introduction}

In 1925, Crohn and Rosenberg documented a case of rectal carcinoma complicating ulcerative colitis (UC) and postulated that the lesion developed as a late manifestation of the

Correspondence to: Dr Kazuichi Okazaki, Third Department of Internal Medicine, Kansai Medical University, 10-15 Fumizono-cho, Moriguchi, Osaka, 570-8506, Japan

E-mail: okazaki@hirakata.kmu.ac.jp

Key words: Smad3, colonic cancer, interleukin-10 disease (1), and many subsequent epidemiological studies have confirmed this increased risk (as high as 34\%) after 25 years of disease (2). In contrast to sporadic colorectal cancers, which develop through the 'adenoma-carcinoma sequence', inflammatory bowel disease (IBD)-associated carcinomas develops through the 'dysplasia sequence'. Although cancers from UC as well as sporadic colorectal carcinoma are hypothesized to arise from a multistep process, the precise mechanism is still unknown.

Interleukin (IL)-10-deficient mice under specific-pathogen free conditions spontaneously develop chronic enterocolitis, a condition phenotypically similar to chronic IBD in humans (3). An increase in the incidence rate of colorectal carcinoma has been observed in conjunction with elevated plasma transforming growth factor (TGF)-B1 levels at 10 to 31 weeks of age (4), which suggests that TGF- $\beta$ may be a key molecule in the development of colon cancer arising from chronic colitis in IL-10-deficient mice. Therefore, this murine IBD model may provide excellent insights into the pathogenetic mechanism of chronic colitis-associated carcinoma.

TGF- $\beta$ is a multifunctional protein that regulates a complex array of cellular processes, including proliferation, differentiation, motility, and death in a cell-specific manner (5). TGF- $\beta$ can inhibit colonic epithelial cell growth, acting as a tumor suppressor (6) and also plays a major role in the negative regulation of immune cell functions, particularly in the gut (7). Loss of TGF- $\beta$ (8) or unresponsiveness to TGF- $\beta 1$ (9) in the colonic epithelium has been associated with the development or progression of inflammation in the colon. However, increased TGF- $\beta$ activity may be involved in tumor development rather than tumor suppression in IL-10deficient mice (5). The role of TGF- $\beta$ in tumor development thus seems to be dual, and dependent on the stage of the tumor. These multiple functions are thought to result from different intracellular signaling pathways. Recent evidence suggests that TGF- $\beta$ is also a key regulator of epithelial-tomesenchymal transition (EMT) in cell phenotypes (10). EMT not only underlies epithelial degeneration and fibrogenesis in chronic degenerative disorders, but also endows dedifferentiated malignant epithelial cells with mesenchymal, migratory, and proteolytic properties that are required for local tumor invasiveness (11). Inhibition of the proinflammatory cytokine IL-1ß at initiation of EMT has been 
found to attenuate fibrogenesis (12), suggesting a causative link between chronic inflammation and EMT. The main downstream signaling pathway for TGF- $\beta$ involves the Smad proteins (13). Although several studies of EMT have suggested that the process involves Smad-independent pathways (14), recent studies using Smad3 knockout mice have indicated that signaling through the Smad3-dependent pathway is required for injury-dependent multistage transition of an epithelial cell to a mesenchymal phenotype (15). Therefore, we focused on Smad3 signaling $(16,17)$, and on the different roles of Smad3 phosphoisoform-mediated signaling in epithelial cells and mesenchymal cells, reported recently (18). Thus, TGF- $\beta$ activates not only TGF- $\beta$ type I receptor (TßRI) but also c-Jun N-terminal kinase (JNK), converting Smad3 into two distinct phosphoisoforms: C-terminally phosphorylated Smad3 (pSmad3C) and linker-phosphorylated Smad3 (pSmad3L). The TßRI/pSmad3C pathway inhibits growth of epithelial cells, while JNK/pSmad3Lmediated signaling promotes ECM deposition by activated mesenchymal cells such as hepatic stellate cells (HSCs) (5). However, it is unclear how Smad3 signaling is involved in the development of colon cancer during long-standing chronic colitis.

In the present study, according to these phosphorylationdefined activities, we studied whether Smad3 phosphoisoforms govern progression from chronic colitis to colonic cancer in an IL-10-deficient mouse model.

\section{Materials and methods}

Animals. C57BL/6-IL-10-deficient mice (aged 4-32 weeks) were purchased from The Jackson Laboratory (Bar Harbor, $\mathrm{ME}$ ). The animals were housed under specific-pathogen free (SPF) conditions and fed autoclaved food and sterile water in the animal facility of the Graduate School of Medicine, Kyoto University. Of these, the IL-10-deficient mice were transferred from SPF to conventional housing conditions at six weeks of age as they spontaneously develop colitis under conventional housing conditions by eight weeks of age. All animal experiments were performed in accordance with our institutional guidelines.

Histology. The entire large intestines were examined in 18 IL-10-deficient mice between 4 and 32 weeks of age. The large intestines were fixed in $4.5 \%$ buffered formaldehyde before embedding in paraffin blocks. For histological analysis, $5-\mu \mathrm{m}$ sections were cut and stained with hematoxylin and eosin (H\&E). The principal histologic distinction was between dysplasia and colorectal carcinoma according to Japanese criteria. Histologic slides involving diagnoses of normal, dysplasia and adenocarcinoma were reviewed independently by two pathologists specialising in gastrointestinal neoplasia.

Domain-specific Abs against the phosphorylated Smad3. Polyclonal anti-phospho-Smad3 antibodies [anti-pSmad3L $\left(\operatorname{Ser}^{207 / 212}\right)$ and anti-pSmad3C $\left.\left(\operatorname{Ser}^{423 / 425}\right)\right]$ were raised against the phosphorylated linker regions and $\mathrm{COOH}$-terminal regions of Smad3 by immunization of rabbits with synthetic peptides. The relevant antisera were affinity purified with the phosphorylated peptides as described previously (16).
Table 1. Serial analysis of intestines in IL-10-deficient mice.

\begin{tabular}{ccccc}
\hline Age (weeks) & $\mathrm{n}$ & Colitis & Dysplasia & Cancer \\
\hline 4 & 3 & 0 & 0 & 0 \\
7 & 1 & 1 & 0 & 0 \\
8 & 2 & 2 & 2 & 0 \\
12 & 2 & 2 & 2 & 1 \\
16 & 2 & 2 & 2 & 2 \\
24 & 2 & 2 & 2 & 2 \\
28 & 4 & 4 & 4 & 4 \\
32 & 2 & 2 & 2 & 2 \\
\hline
\end{tabular}

Immunohistochemistry. Immunohistochemical staining was performed on formalin-fixed, paraffin-embedded tissue sections. The sections were deparaffinized in xylene, and rehydrated in graded alcohols. Antigen retrieval was done by microwave irradiation in $0.01 \mathrm{M}$ sodium citrate buffer ( $\mathrm{pH}$ 6.0) for $15 \mathrm{~min}$. After cooling, the endogenous peroxidase activity was blocked by incubation in $3 \% \mathrm{H}_{2} \mathrm{O}_{2}$ in methanol for $10 \mathrm{~min}$. After rinsing with TBS containing $0.1 \%$ Tween-20 (TBST), non-specific antigens were blocked by preincubation with $1 \%$ bovine serum albumin (Nakarai, Kyoto, Japan). The sections were incubated overnight with the following primary antibodies: anti-mouse p53 $(1.0 \mu \mathrm{g} / \mathrm{ml}$, Abcam, Cambridge, $\mathrm{UK})$, anti-pSmad3L $(1.0 \mu \mathrm{g} / \mathrm{ml})$ and anti-pSmad3C $(1.0 \mu \mathrm{g} /$ $\mathrm{ml}$ ). After rinsing with TBST, the sections were incubated with peroxidase-labeled polymer conjugated to goat antirabbit immunoglobulin for $1 \mathrm{~h}$ at room temperature. The peroxidase activity was visualized with 3,3'-diaminobenzidine (Vector Laboratories, Burlingame, CA) counterstained with Mayer's hematoxylin (Merck, Darmstadt, Germany), and mounted under coverslips. The evaluation of immunoreactivity was performed by microscopy (Olympus BX 50, Tokyo, Japan). Immunohistochemistry was scored by pathologists in double-blind fashion according to staining proportions as follows: 0 , no staining seen; 1 , staining seen in $5-30 \%$ of cells; 2 , staining seen in $>30 \%$ of cells.

Statistical analysis. Statistical evaluation was done using the nonparametrical Mann-Whitney U ranking test. Values were based on two-tailed statistical analysis.

\section{Results}

Development of colorectal dysplasia and carcinomas in IL-10-deficient mice. We confirmed a previous report that IL-10-deficient mice develop colitis after 7 weeks. We found that mice developed dysplasia or cancer after 8 to 12 weeks, respectively (Table I; Fig. 1). We observed no metastasis in the mesenteric lymph nodes or liver in any mice. We also observed that the small intestine was not affected.

Smad3 phosphorylation of $\mathrm{COOH}$-terminals and linker regions. Immunohistochemical analysisis was performed on mice from each stage to detect Smad3 phosporylation. pSmad3C was detected without significant difference between 


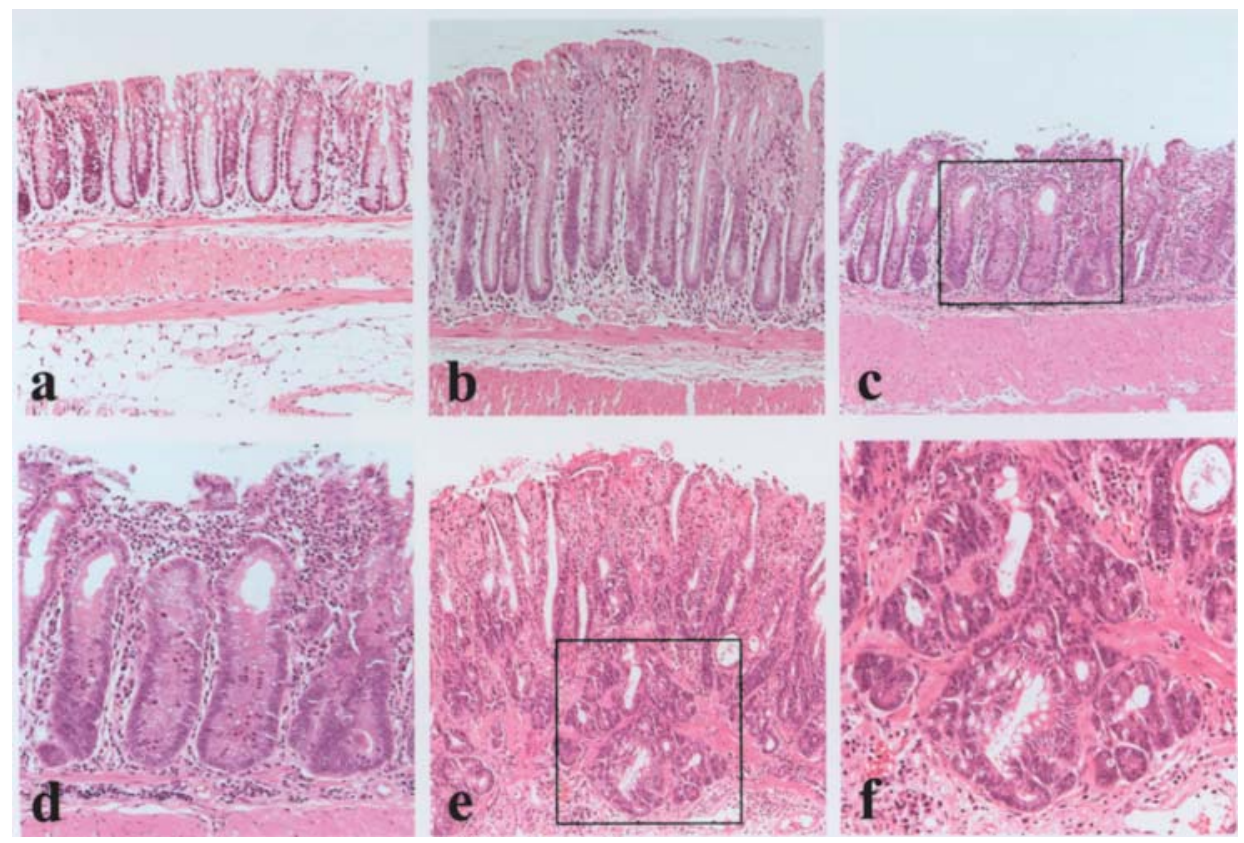

Figure 1. Histopathological findings of the colorectum in IL-10-deficient mice using hematoxylin and eosin staining (H\&E). Normal colonic mucosa (a, $\mathrm{x} 40$ ). IL-10-deficient mice developed colitis (b, x40) after 7 weeks. Dysplasia (c, x40; d, x200) and cancer (e, x40; f, x200) were found after 8-12 weeks.

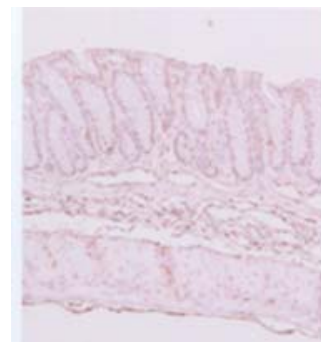

a

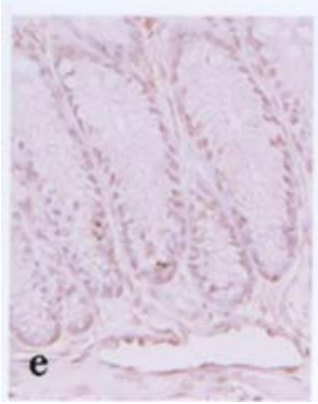

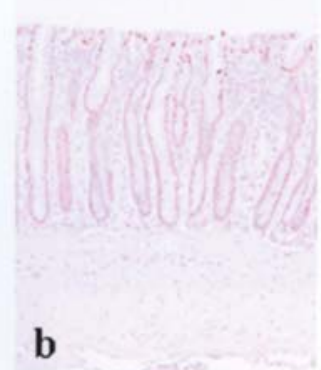

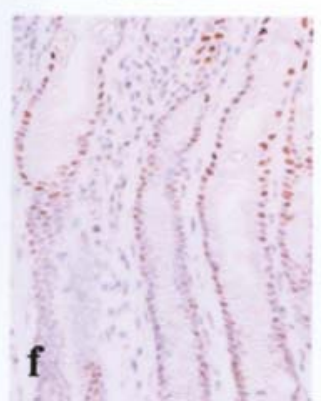

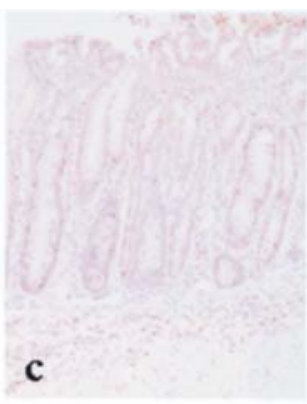

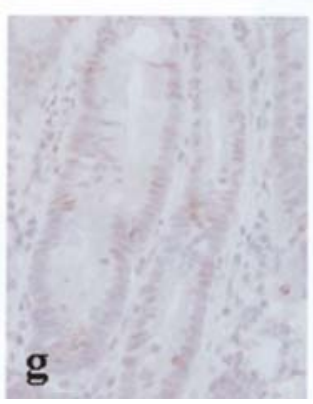

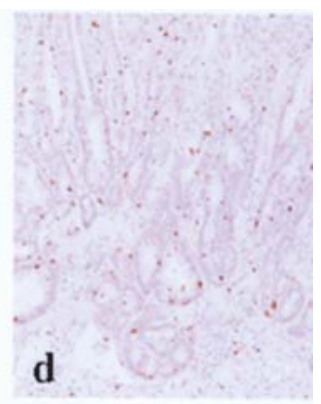

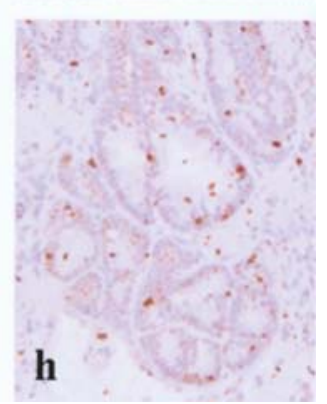

Figure 2. Immunohistochemical findings of the colorectum in IL-10-deficient mice using anti-pSamd3C antibody. pSmad3C was detected without significant difference between stages. Normal mucosa (a, x40; e, x200); colitis (b, x40; f, x200); dysplasia (c, x40; g, x200); cancer (d, x40; h, x200).

stages (Figs. 2 and 5). On the other hand, pSmad3L detection levels gradually increased from dysplasia to adenocarcinoma (Figs. 3 and 5). pSmad3L was expressed in dysplasia and cancer cells, but not in inflamed mucosa cells, even in the mice with cancer.

p53 expression in colorectal cancers. To determine p53 expression, all mice were subjected to immunohistochemical analysis using rabbit anti-mouse p53 polyclonal antibody. p53 was detected only in the mice with colonic cancer (Figs. 4 and 5). Dysplasia of the colorectal epithelium was not stained with anti-p53 antibody (Figs. 4 and 5). In 5 out of the 10 mice with cancer, the cancer cells were stained, however very few cells were p53 positive and even so stained weakly (Figs. 4 and 5).

\section{Discussion}

Colon cancer in patients with ulcerative colitis is thought to be associated with long-standing tissue injury and chronic inflammation (19). The relationship between chronic inflammation and cancer dates back to Virchow, who, in 

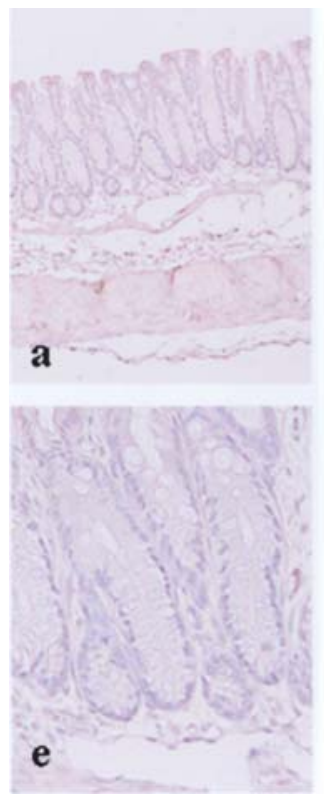
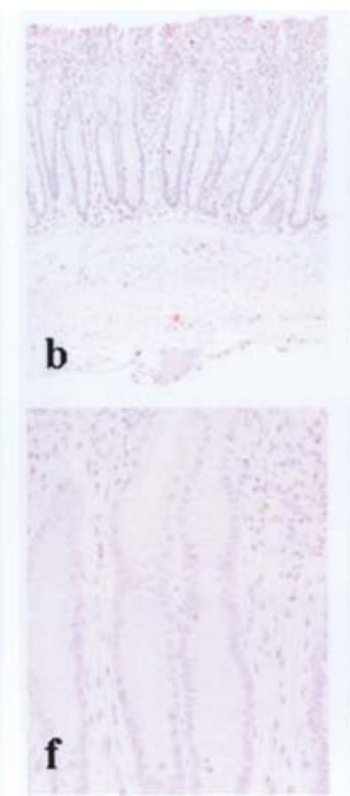
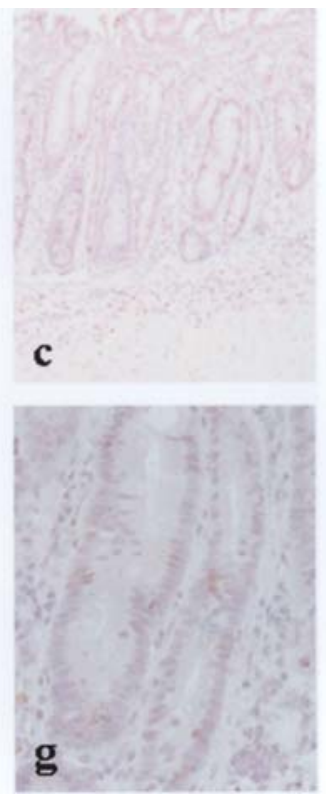
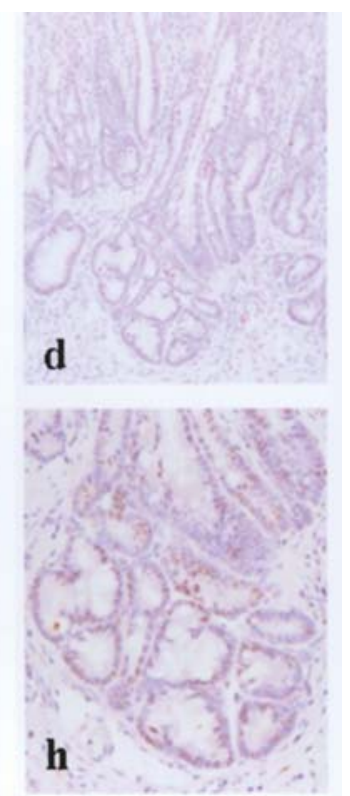

Figure 3. Immunohistochemical findings of the colorectum in IL-10-deficient mice using anti-pSamd3L antibody. pSmad3L detection levels gradually increased from dysplasia to adenocarcinoma. Normal mucosa (a, x40; e, x200); colitis (b, x40; f, x200); dysplasia (c, x40; g, x200); cancer (d, x40; h, x200).
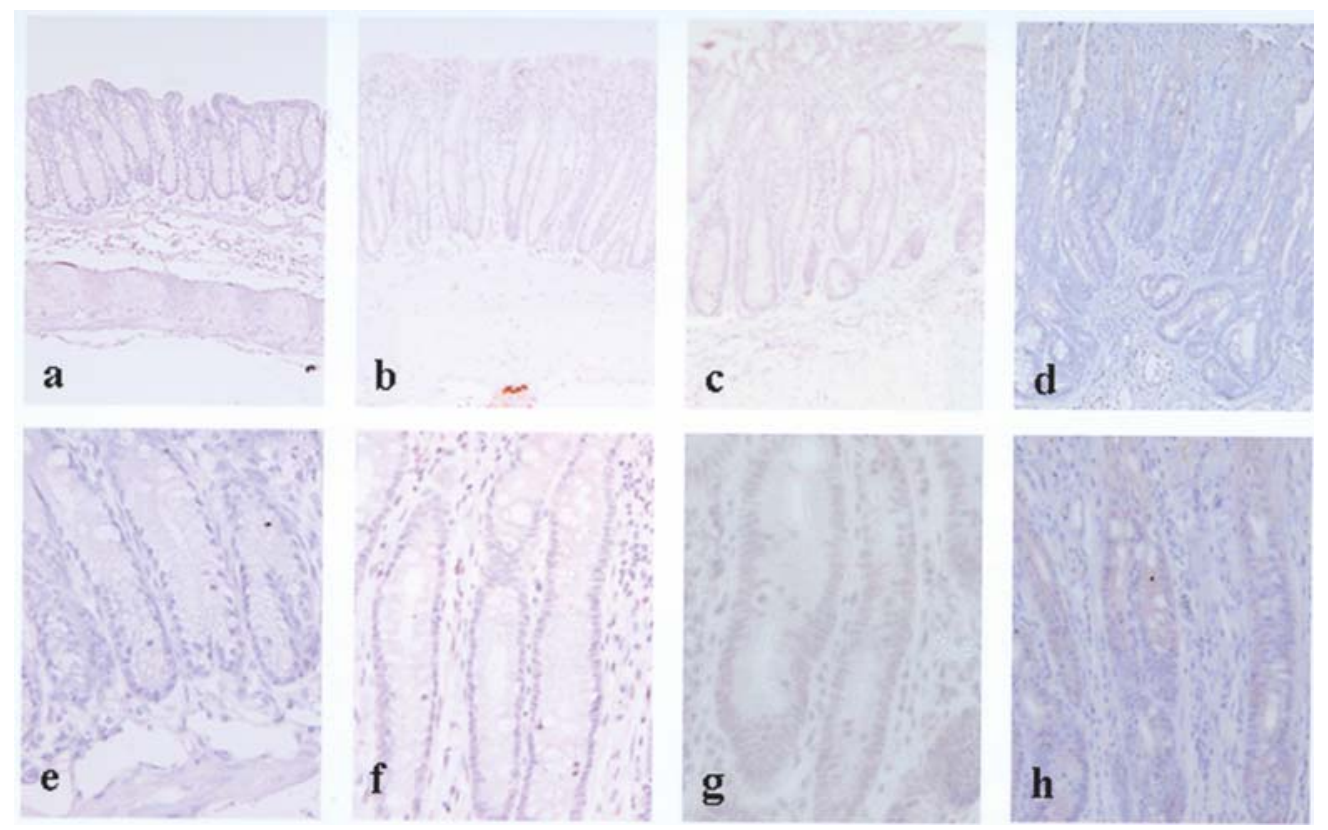

Figure 4. Immunohistochemical findings of the colorectum in IL-10 deficient mice using anti-p53 antibody. In 5 out of 10 mice with cancer, a few cancer cells were stained weakly. Normal (a, x40; e, x200); colitis (b, x40; f, x200); dysplasia (c, x40; g, x200); cancer (d, x40; h, x200).

1863, hypothesized that the origin of cancer was at sites of chronic inflammation (20). Although the relation between chronic inflammation and cancer has been well established in general, the molecular mechanisms involved in the process remain unclear. Certainly, chronic inflammation leads to increased oxidative stress. Leukocytes and other phagocytic cells generate reactive oxygen and nitrogen species, which, in turn, can damage proliferating epithelial cells. Also, chronic inflammation appears to promote the apoptosis of normal epithelial cells which can lead to a compensatory proliferative response by the remaining tissue.
Our present study confirmed that IL-10-deficient mice, spontaneously develop colonic dysplasia and cancer at a high rate following chronic colitis (4). In IL-10-deficient mice, it has been shown that serum levels of TGF- 11 significantly increase in mice with dysplasia and cancer, compared to those without tumors (4). This led us to a hypothesize that genetic alterations in other members of the TGF- $\beta$ receptor signal transduction pathway are involved in the development of colon cancer in long-standing colitis. TGF- $\beta$, which can potently inhibit epithelial cell growth to act as a tumor suppressor (10), is also a key regulator of epithelial-to- 
score (a) Smad3C

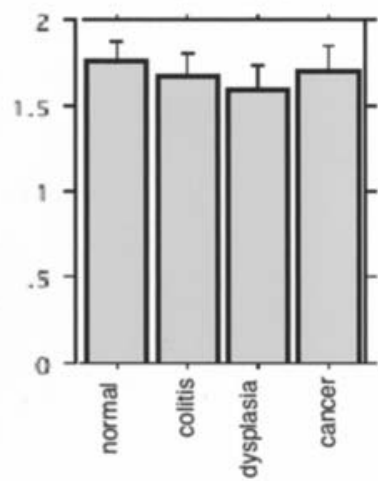

(b) Smad3L

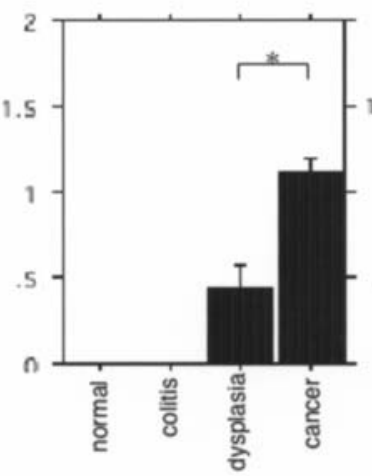

(c) p53

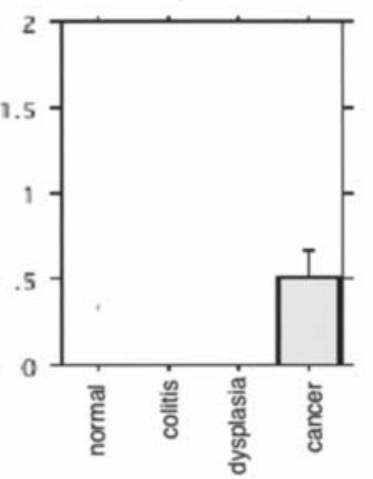

Figure 5. Immunohistochemical scores of Smad3C, 3L and p53. Immunohistochemistry was scored by pathologists in double-blind fashion according to staining proportions as follows: 0 , no staining seen; 1 , staining seen in 5 to $30 \%$ of cells; 2 , staining seen in $>30 \%$ of cells. pSmad $3 \mathrm{~L}$ detection levels increased significantly from colitis to dysplasia $(0.417 \pm 0.513)$ to adenocarcinoma $(1.100 \pm 0.316)(\mathrm{p}<0.05)$. In normal and inflamed mucosa, even in cancerous mice, pSmad3L was not detected. Cancer cells were also stained with p53, however very few cells were positive and even so stained weakly (0.500 \pm 0.527$)$. pSmad3C was detected without any significant difference between stages. Scores of pSmad2C staining in normal mucosa, colitis, dysplasia, and cancer were: $1.750 \pm 0.452,1.667 \pm 0.492,1.583 \pm 0.515$, and $1.700 \pm 0.483$, respectively.

mesenchymal transition (EMT) in cell phenotypes. EMT may be related to the loss of tumor responsiveness on the growth inhibitory effect of TGF- $\beta$ and at the same time to the TGF- $\beta$ induced angiogenesis, and local and systemic immunosuppression. During carcinogenesis, tumors show EMT, thereby becoming insensitive to TGF- $\beta$-mediated growth inhibition while showing increased tumor invasion and metastasis $(10,21)$.

TGF- $ß$ signaling is initiated when this ligand induces the formation of a heteromeric complex composed of TGF- $\beta$ receptor type I (TßRI) and type II (TßRII). This allows TßRII to phosphorylate TßRI, which then transmits the signal through phosphorylation of receptor-regulated Smads (R-Smads) such as Smad2 and Smad3 (22). R-Smads are directly phosphorylated at $\mathrm{COOH}$-terminal SXS regions by TßRI and then undergo formation of heteromeric complexes with Smad4 (23). Activated Smad complexes are then translocated into the nucleus, where they regulate the expression of target genes both by direct DNA binding and through interaction with other transcription factors, coactivators, and co-repressors (24). Smads contain two highly conserved domains, the Mad homology 1 (MH1) and 2 (MH2) domains, which are connected by interposed linker regions (25). Although the MH1 domains can interact with DNA, the MH2 domains are endowed with transcriptional activation properties (23). In human colorectal cancer, somatic mutation of the Smad4 (18q21) or Smad2 gene (18q21) has been detected in the MH2 domain, but mutations of Smad3 (15q21), Smad6 (15q21), and Smad7 (18q21) genes have not been detected so far (26). On the other hand, Smad3-deficient mice develop colorectal carcinoma (27). Although several studies of EMT have suggested that the process involves Smad-independent pathways (23), there is evidence from Smad3-deficient mice that signaling through the Smad3-dependent pathway is required for injurydependent multistage transition of an epithelial cell to a mesenchymal phenotype (15). As a consequence, we have focused on Smad3 signaling $(16,17)$ and successfully developed polyclonal antibodies, which specifically recognize the phosphorylated linker regions and phosphorylated COOH-terminal SXS regions of Smad3 (17). Using these antibodies, we recently reported that Smad3 phosphorylated at linker regions or $\mathrm{COOH}$-terminal regions existed as separate molecules with different functions and transmitted distinct signals (16-18). We also previously reported that as neoplasia progresses from normal colorectal epithelium through adenoma to invasive adenocarcinoma with distant metastasis, nuclear pSmad3L gradually increases while pSmad3C decreases (28). The TßRI/Smad pathway is widely represented in most cell types and tissues studied to date, and additional pathways are activated following cell stimulation by TGF- $\beta$ in specific contexts. The most prominent pathways are mediated by the mitogen activated protein kinase (MAPK) family, which consists of the extracellular signalregulated protein kinase pathways c-Jun NH2-terminal kinase (JNK) and p38 pathways (29). TGF- $\beta$ induces activation of MAPK pathways through the upstream mediators Ras, RhoA, PP2A, and TGF- 3 -activated kinase I (17). Thus, TGF- $\beta$ activates not only TßRI but also JNK, which converts Smad3 into two distinctive phosphoisoforms: pSmad3C and pSmad3L (5). Therefore, during sporadic human colorectal carcinogenesis, the shift from TßRI/ $\mathrm{pSmad} 3 \mathrm{C}$-mediated to $\mathrm{JNK} / \mathrm{pSmad} 3 \mathrm{~L}$-mediated signaling is a major mechanism orchestrating a complex transition of TGF- 3 signaling (5).

In the present animal study, we observed a significant increase in $\mathrm{pSmad} 3 \mathrm{~L}$ as neoplasia progressed from normal colorectal epithelium through dysplasia. Our study showed that, unlike human sporadic colon cancer, there were no changes in the phosphorylation of $\mathrm{pSmad} 3 \mathrm{C}$ in the murine model. Moreover, no mice showed deep invasion and metastasis of cancer, which suggested that the malignant potential might be low in IL-10-deficient colitis.

The p53 mutation is known as the most common cancerrelated genetic change (30). The overexpression of p53 occurs frequently in ulcerative colitis-associated colorectal carcinoma regardless of stage and pathological characteristics (31). In our results, p53 could only be detected in 
some cancerous cells, and positive staining was weak. These findings, together with previous reports suggest that $p 53$ mutations are unlikely to be involved in the malignant transformation of epithelial cells in mice (4). Also, inactivation of $p 53$ may occur in the late stages of colorectal cancers developing in IL-10-deficient mice, thus being present in only a small number of tumor cells and barely detectable by the methods used in our study.

In conclusion, the phosphorylation of Smad3L may play an important role in the carcinogenesis of colorectal cancer associated with chronic colitis in IL-10-deficient mice. Further studies in human ulcerative colitis are necessary for the clarification of colitic cancer.

\section{Acknowledgements}

This study was partly supported by Grants-in-Aid for scientific program (C) from the Ministry of Science and Culture of Japan (18590755), and by Grants-in-Aid from the Health, Labor and Welfare Ministry of Japan.

\section{References}

1. Crohn BB and Rosenberg H: The sigmoidscopic picture of chronic ulcerative colitis (non-specific). Am J Med Sci 170: 220-228, 1925.

2. Kewenter J, Ahlman H and Hulten L: Cancer risk in extensive ulcerative colitis. Ann Surg 188: 824-828, 1978.

3. Reninick DM, Fort MM and Davidson NJ: Studies with IL-10-/mice; an overview. J Leukoc Biol 61: 389-396, 1997.

4. Strulan S, Oberhuber G, Beinhauer BG, Tichy B, Kappel S, Wang $J$ and Rogy MA: Interleukin-10-deficient mice and inflammatory bowel disease associated cancer development. Carcinogenesis 22: 665-671, 2001.

5. Matsuzaki K and Okazaki K: Transforming growth factor-beta during carcinogenesis: the shift from epithelial to mesenchymal signaling. J Gastroenterol 41: 295-303, 2006.

6. Moses HL, Yang EY and Pietenpol JA: TGF-beta stimulation and inhibition of cell proliferation: new mechanistic insights. Cell 63: 245-247, 1990.

7. MacDonald TT: Effector and regulatory lymphoid cells and cytokines in mucosal sites. Curr Top Microbiol Immunol 236: 113-135, 1999.

8. Maloy KJ and Powrie F: Regulatory T cells in the control of immune pathology. Nat Immunol 2: 816-822, 2001.

9. Eppert K, Scherer WS, Ozcelik H, et al: MADR maps to $18 \mathrm{q} 21$ and encodes a TGF- $\beta$-regulated MAD-related protein that is functionally mutated in colorectal carcinoma. Cell 86: 543-552, 1996.

10. Zavadil $\mathrm{J}$ and Bottinger EP: TGF- 3 and epithelial-to-mesenchymal transitions. Oncogene 24: 5764-5774, 2005.

11. De Caestecker MP, Piek E and Roberts AB: Role of transforming growth factor- $\beta$ signaling in cancer. J Natl Cancer Inst 92: 1388-1402, 2000.
12. Kolb M, Margetts PJ, Anthony DC, et al: Transient expression of IL-1beta induces acute lung injury and chronic repair leading to pulmonary fibrosis. J Clin Invest 107: 1529-1536, 2001.

13. Heldin $\mathrm{CH}$, Miyazono $\mathrm{K}$ and ten Dijke P: TGF- $ß$ signaling from cell membrane to nucleus through SMAD proteins. Nature 390: 465-471, 1997.

14. Derynck R and Zhang YE: Smad-dependent and Smadindependent pathways in TGF- $\beta$ family signaling. Nature 425 : 577-584, 2003.

15. Saika S, Kono-Saika S, Ohnishi Y, et al: Smad3 signaling is required for epithelial-mesenchymal transition of lens epithelium after injury. Am J Pathol 164: 651-663, 2004.

16. Furukawa F, Matsuzaki K, Mori S, et al: p38 MAPK mediates fibrogenic signal through Smad3 phosphorylation in rat myofibroblasts. Hepatology 38: 879-889, 2003.

17. Mori S, Matsuzaki K, Yoshida K, et al: TGF-ß and HGF transmit the signals through JNK-dependent Smad2/3 phosphorylation at the linker regions. Oncogene 23: 7416-7429, 2004.

18. Yoshida K, Matsuzaki K, Mori S, et al: Transforming growth factor- $\beta$ and platelet-derived growth factor signal via c-Jun $\mathrm{N}$ terminal kinase-dependent Smad2/3 phosphorylation in rat hepatic stellate cells after acute liver injury. Am J Pathol 166: 1029-1039, 2005.

19. Ekbom A, Helmick C, Zack $M$ and Adami HO: Ulcerative colitis and colorectal cancer. A population-based study. N Engl J Med 323: 1228-1233, 1990 .

20. Balkwill F and Mantovani A: Inflammation and cancer: back to Virchow? Lancet 357: 539-45, 2001.

21. Oft M, Peli J, Rudaz C, Schwarts H, Beug H and Reichmann E: TGF-betal and Ha-Ras collaborate in modulating the phenotypic plasticity and invasiveness of epithelial tumor cells. Genes Dev 10: 2462-2477, 1996.

22. Shi Y and Massague J: Mechanisms of TGF-beta signaling from cell membrane to nucleus. Cell 113: 685-700, 2003.

23. Derynck R and Zhang YE: Smad-dependent and Smadindependent pathways in TGF-beta family signaling. Nature 425: $577-584,2003$.

24. Kretschmar M, Doody J, Timokhina I and Massague J: A mechanism of repression of TGFbeta/Smad signaling by oncogenic Ras. Genes Dev 13: 804-816, 1999.

25. Robinson MJ and Cobb MH: Mitogen-activated protein kinase pathways. Curr Opin Cell Biol 9: 180-186, 1997.

26. Miyaki M and Kuroki T: Role of Smad4 (DPC4) inactivation in human cancer. Biochem Biophys Res Commun 306: 799-804, 2003.

27. Zhu Y, Richardson JA and Parada LF: Smad3 mutant mice develop metastatic colorectal cancer. Cell 94: 703-714, 1998.

28. Yamagata H, Matsuzaki K, Mori S, et al: Acceleration of Smad2 and Smad3 phosphorylation via c-Jun NH2-terminal kinase during human colorectal carcinogenesis. Cancer Res 65: 157-165, 2005 .

29. Mulder KM: Role of Ras and Mapks in TGFbeta signaling. Cytokine Growth Factor Rev 11: 23-35, 2000.

30. Vogelstein B: Cancer. A deadly inheritance. Nature 348: 681-682, 1990.

31. Harpaz N, Peck AL, Yin J, et al: p53 protein expression in ulcerative colitis-associated colorectal dysplasia and carcinoma. Hum Pathol 25: 1069-1074, 1994. 